\title{
The Effects of Chinese Cultural Digital Product Consumption toward the Motivation to Learn Chinese Culture: A Study of Chinese TV Series Watching among Thai-teenage Users
}

\author{
Tanin Tirasawasdichai ${ }^{1}$, Korakot Pookayaporn ${ }^{2}$ and Diana Tsoy $^{3}$ \\ ${ }^{1}$ Ph.D. candidate School of Media and Communication \\ Shanghai Jiao Tong University, Shanghai, China \\ Email: tanin.ti [AT] ku.th \\ ${ }^{2}$ Ph.D. candidate School of Media and Communication \\ Shanghai Jiao Tong University, Shanghai, China \\ Email: ice.korakot [AT] gmail.com \\ ${ }^{3}$ Ph.D. candidate School of Media and Communication \\ Shanghai Jiao Tong University, Shanghai, China \\ Email: diana.tsoy [AT] gmail.com
}

\begin{abstract}
The diffusion of Chinese communication channel and digital products is very rigorous in the era of media technological advancement. People absorb cultural attitude via cultural product consumption, along with digital online platform, accession is much more easily than before. In Thailand, majority of netizens spend a lot of time to video consumption in a huge amount of numbers confirmed by triple digit growth in digital platform and applications downloaded. In order to deepen our understanding about media effects, this research proposal aims to study how Chinese TV series consumption shapes Thai netizens cultural knowledge and attitude on the basis of cultivation and gratification theory. Both quantitative and qualitative paradigm are designed as methodology to study among netizens in Thailand.
\end{abstract}

Keywords-Chinese TV series, cultural digital product, Chinese culture, cultural acceptance.

\section{INTRODUCTION}

The development of Chinese communication channel is very rigorous recently with high effort to enter international market (Keane, 2019), more than a billion of internet users all around the world reach Chinese application via smart phone. In Thailand, Chinese TV series as cultural digital product are getting more and more popularity among internet users, especially, teenager which is the major part of netizens.

On average, Thai internet users spend 3 hours and 44 minutes to consume online content, $98 \%$ spend these times on online video ${ }^{1}$. Tencent Video, one of the biggest platforms online streaming video providers chose Thailand as the first place to expand their service via We TV, the online streaming video application which has grown up more than $700 \%$ within less than two years ${ }^{2}$. More than 500,000 users are expected to subscribe and watch Chinese TV series via online channel daily, famous TV series could even drive total number of application download from only one story. For example, Por ra ma jarn rat ti marn (The master of devil clan) has attracted total number of application download grew about $250 \%{ }^{3}$. These digit data show that how Chinese TV series popular in Thailand.

The dissemination of Chinese TV series does not only convey entertainment to internet users but also convey the attitude, value, viewpoint, culture, behavior including motivations in many aspects to internet users, there are some comments from Chinese TV series watchers suggested that the content of TV series should give a full dimensions of cultural aspects (Fu et al., 2020). Currently, China can be realized as new trend fashion in many aspects particularly to Thailand, there is a long-time history relationship between China and Thailand, a lot of citizens have their ancestor as Huaqiao (the people who moved from China to settle down in Thailand). Accordingly, it is undeniable that the Chinese

\footnotetext{
${ }^{1}$ https://thestandard.co/wetv/

2 https://brandinside.asia/key-success-of-wetv-thailand/

${ }^{3}$ https://www.blognone.com/node/112591
} 
culture, which has already been strong, is turning stronger from the effects of TV series as digital cultural product among Thai-teenagers.

Although, there are many evidences show how popular and widespread Chinese cultural digital products, especially Chinese TV series are, the study of cultural acceptance and motivations to learn Chinese culture are very limited, particularly, the in-depth understanding of process of cultural acceptance and other motivations according to the effects of TV series consuming.

The motivation of learning in new culture like Chinese culture could be initiated by closer experiences in each environment. For example, Taddese (2019) found that international students in Chinese university are curious to learn Chinese language and Chinese culture from their inner feeling, not only because the course is compulsory but as they keen to learn, corresponding to the study of Gong, Ma, Hsiang and Wang (2020) mentioned that there is motivational shift about learning Chinese in students before and after relocation to China, they had their motivation enhanced and expected to continue learning Chinese in the future.

Chinese digital cultural product consumption is also a very important factor to cultural acceptance, it could be the starting point of learning in Chinese culture or leading to external behaviors of consumers to understand the different culture, travel to China, contact with Chinese people or even for job and business opportunities, especially, in the era of globalization which we are living among differences. Those are the objectives of this research study; the literature review shows about previous work in cultural and digital product field following by the research design in last section.

\section{LITERATURE REVIEW}

\subsection{Uses and Gratifications Theory}

As the data in previous part depicted that how popular and widely spread Chinese TV series are in Thailand, the story of each TV series attracts internet users to be sunk in the content. Huang (2015) found that one reason that university students consume TV series is since the content of story is entertaining and attractive. Moreover, many other reasons supported such as gratification obtained from watching online TV series which could be accessed anytime and wide availability of internet (Li, 2013) and motivation to gain gratification from watching TV (Rubin, 1983). Therefore, we can see that gratification could be realized as the first prior of watching TV or TV series content no matter online or offline platform. As this research aims to understand how consumption of Chinese TV series among internet users in Thailand affects to cultural acceptance, we can apply the Uses and Gratifications theory as the basis of this research study. Papacharissi (2009) mentioned that Uses and Gratifications theory states media usage of consumers in order to satisfy their specific needs or wants or desires, they may use it for entertainment, information seeking, communicate with other individuals, participate in online virtual community or to pursue self-expression. Every single use response to each particular need or gratification, then, researcher could design and find the motivations behind media usage. Some previous studies revealed that the main reasons of TV viewing are gratification gained from the content of story, from the process of obtaining the program and social interactions from program consuming (Stafford et al., 2004). Entertainment from content of program story plays crucial role in attracting viewers and creating fanclub of that program, but rather than the enjoyable time of consumption, the other reason is not to be escapist and information seeking (Rubin, 1983).

Even the binge-watchers (the people who spend a lot of time watching many episodes) of TV series also perceived other aspects of story content beyond only the entertainment. Steiner and Xu (2018) indicated that motivations for bingewatch are catching up, relaxation, sense of completion, cultural inclusion and improved viewing experience.

The basis of uses and gratifications theory will bring this research to study to understanding in-depth of motivation in Chinese TV series consuming among Thai-teenage as internet users. The objective of the first section is to get thick description of experiences in Chinese TV series watching, since formerly, there are only TV series program from Japan and Korea, the basis of this theory would help us understand better in motives of changing from other countries' TV series to Chinese TV series' consumption and popularity.

Beyond exploring the in-depth understanding of internet users about their behavior and attitude to Chinese TV series culture, we can also understand the incentives and motivations of watching or consuming, This process could help us clarify a better conceptual framework and variables in study because in-depth understanding of thick description could provide us the new factors or issues that we never realize in research study before. Then, the next section is about the effect of media consuming to the awareness and perception from content of TV series which we interest here about the cultural acceptance from TV series watching.

\subsection{Cultivation Theory}

The cultural awareness and perception according to consuming TV series are obviously affected from content of story which was created by different producers and originals. It is obviously that there are influences of story content 
from program to the watchers. Gerbner, Gross,Morgan, Signorielli, and Shahnahan (2002) stated that the heavy viewers are more likely to believe and perceive their real life are similar to the reality and content showed on TV. Moreover, viewers are presumed to have the same sort of beliefs and world views.

Impacts of TV program content came from producers or creators as senders or the origins of effects. Wang (2020) revealed that creator's experiences and emotional engagement are enriched when they were applied in idea generation, brainstorming and design process of digital content, corresponding to Gevorgyan and Manucharova (2015) mentioned that communicators will try to increase similarity of communication between them and audiences for a better communication outcome. Consequently, we can see that media effects from content of TV series could be leaded by the content producers. While in consumer part, they will be the receiver of effects from what producer convey via the content of TV series story. However, in some kinds of digital cultural product, audiences are not just the passive obtainer, they also communicate and interact both between audiences and audiences and audiences and producers. For instance, Thomas (2011) stated that the emergence of Web 2.0, there has been 'a phenomenon growth in scale and scope of fan communities', fan and follower of digital cultural product also influence to producer and production process (Pearson, 2010), the influence of consumers is empowered in creating digital content which brought to the new mix term of two words as 'produsage' or 'prosumer' depicted that audiences are also participating in producer part. In online fictions and novels as cultural digital product, readers even pay money as sponsors to give incentives to writers, they participate with writers by commenting, voting and sending money including rising up the community of online readers to share and exchange their opinion (Tian and Adorjan, 2016). Fan readers could be realized as a very important intermediary in expansion of digital media content (Dwyer, 2019), their basis of trust to the community of readers plays a very important role to percentage of global GDP that cultural and creative industries generate each year, as they feel enjoyed with the content brought to the volunteer of translation to share with readers community (Shim, Yecies, Ren and Wang, 2020).

We can see that the inner feeling of cultural digital product fan is very strong which leaded to the effects of media consumption. Hence, the cultivation of media consumption is very well explainable for the effects of TV series consuming to viewers' attitudes, since we can see that the higher inner and consumption product are, the higher level of awareness and perception in content and other factors behind contents are too. The logic of media makes format and style of media served as means of perceiving the world, the rooting of media cultural consciousness is consumer needs to engage and understand content story (Altheide \& Snow, 1991).

The development of media technology plays a crucial role to media effects from TV series consumption that the time spends on watching are much more than in the past. Since, in the past we can only watch story content from program of TV, digital devices such as DVD, VCD or recorded programs are the main sources of content (Bury and Li, 2013). On the other hand, digital devices in the era are much more easily to access which move consumers to stay closer to content of the program. For example, the binge-watch behavior of consumers via internet and online channel (Walton-Pattison, Dombrowski and Presseau, 2016) or the willing to expand the time while watching in one-sitting or determined to bingewatch habits (Petersen, 2016). These are the characters that make consumers become more easily to access TV series which would affect to cultural acceptance more rapidly.

In order to understand in-depth process of awareness and perception of content including cultural acceptance and motivations to learn Chinese culture according to the consuming to Chinese TV series among Thai teenagers, we can identify the following research questions for a better understanding of media effects on motivations to learn new culture:

1. What are the motivations of Thai-teenage internet users in consuming Chinese TV series?

2. What does individual perceive while watching Chinese TV series?

3. How Chinese TV series watching affects point of view about China?

4. How individual's Chinese cultural perception change compared before and after becoming Chinese TV series watchers?

\section{How Chinese TV series consumption affects to motivations to learn Chinese culture?}

After conducting in-depth interview for qualitative part, then we will clarify the conceptual framework from both literature review data and qualitative analysis. However, as we know that uses and gratifications theory is the basis of TV series consumption while, cultivation theory is the basis of cultural awareness and acceptance. The conceptual framework is drawn from gratification and cultivation model according to Bilandzic and Rössler (2004), since gratification could be the motivation to TV exposure which affects to cultivation process in the next step. However, in this study, TV exposures are in online channel, digital media or internet video streaming instead of traditional TV.

The conceptual framework is as follow: 
Gratification and Cultivation Model

Uses and Gratifications Theory

Cultivation Theory

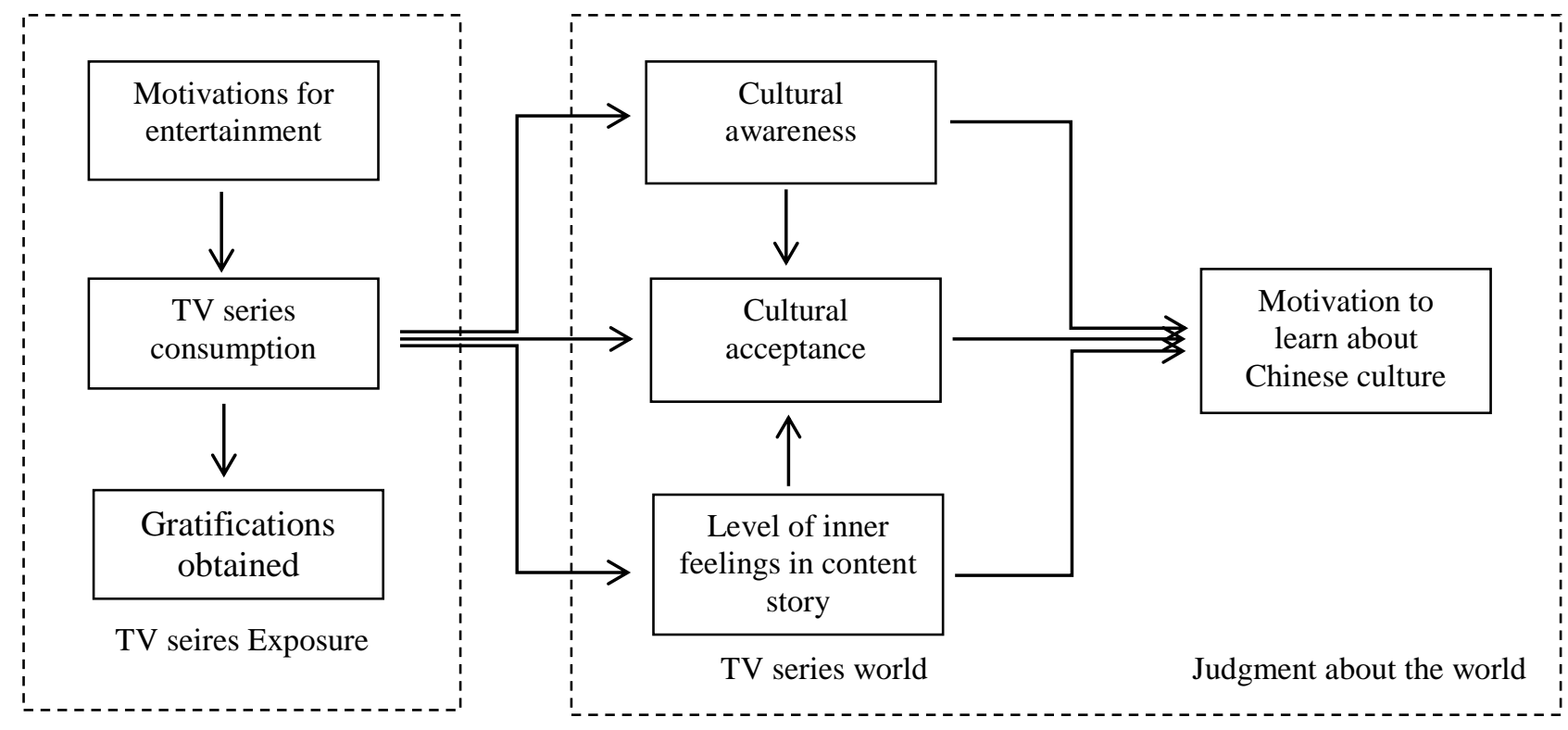

Figure 1: Conceptual Framework

\subsection{Research Hypotheses}

H1: Motivations for entertainment affect to TV series consumption in a positive direction.

H2: TV series consumption affects to Gratifications obtained in a positive direction.

H3a: TV series consumption affects to Cultural awareness in a positive direction.

H3b: TV series consumption affects to Cultural acceptance in a positive direction.

H3c: TV series consumption affects to Level of inner feelings in content story in a positive direction.

H4: Cultural awareness affects to Cultural acceptance in a positive direction.

H5: Level of inner feelings in content story affects to Cultural acceptance in a positive direction.

H6: Cultural awareness affects to Motivation to learn about Chinese culture in a positive direction.

H7: Cultural acceptance affects to Motivation to learn about Chinese culture in a positive direction.

H8: Level of inner feelings in content story affects to Motivation to learn about Chinese culture in a positive direction.

\section{RESEARCH METHODOLOGY}

There are several research tools would be used in this methodology, by using mix method of research study, we can double check and double confirm of empirical results. The following are the composite of this research methodology:

\subsection{Research design}

This research will use mixed method which consist of both qualitative and quantitative analysis. Starting from document study or literature review to identify research questions, then writing a draft of in-depth interview for qualitative research as the first part, next, clarify the main idea of findings to create conceptual framework of quantitative research, as well as the research hypothesis of this study which is expected to use statistical analysis structural equation model (SEM) to analyze cause and effect of independent variables, mediator variables and dependent variables. Finally, summarize the empirical findings and the contributions of this research study.

\subsection{Population and Samples}

The population of this research study is Thai-teenage internet users which are university students in Thailand since they are the majority part of total number of internet users. However, it is uncountable population for total number of teenage internet users. Therefore, we have to use research sample to estimate the value of population. Since, this research uses mixed method in research design; the qualitative research will be conducted first following by quantitative research. For qualitative research, about 40-50 respondents are expected to be conducted in-depth interview, samples recruited by purposive snowball method. After analyzing qualitative data, we will create the conceptual framework consisting of independent, mediator and dependent variables. In this part, the questionnaire would be used as a tool to 
collect quantitative data, there are no less than 400 respondents expected to be conducted in this collection because with the unknown population, 400 is the number that large enough to limit margin of error in estimation, so we will use the return rate at number of 400 or higher.

\subsection{Research tools}

Research tools can be divided into two parts; qualitative and quantitative. For qualitative research, the semistructure in-depth interview would be used as research tool, the interview guide must be able to answer research questions. The sampling method is purposive snowball sampling, since we could be infused in deep data from respondents with about 30-60 minutes length of duration. For quantitative research tool, the questionnaire would be used as data collection tool asking about independent, mediator and dependent variables. The pilot test would be first conducted before real data collection to make sure that reliability of questionnaire is no problem.

\subsection{Measurement and questions}

After in-depth interview is conducted, the results and thematic coding of qualitative analysis will be used as the guideline of conceptual framework in quantitative study part. Survey will be used as data collection tool to get quantitative data for statistical and numerical analysis. The questionnaire would be designed upon the themes of qualitative analysis and aforementioned conceptual framework, 5-level Likert scale will be used in questionnaire for each variable; motivations for entertainment would measure the entertainment sought from Chinese TV series, TV series consumption measures time spend and quantity of consumption, gratifications obtained measure the satisfaction of TV series watch, Cultural awareness measures how viewers perceive about culture expression in program's content, Cultural acceptance measures familiarity and understanding of Chinese culture, inner feeling in content measures how viewers enjoy and dedicate themselves into content story and finally, motivations to learn Chinese culture measures how aspired the watchers are to learn Chinese culture in new dimension according to TV series watching.

\subsection{Data analysis}

The thematic coding would be used to code the data from in-depth interview of respondents, at the same time, theme of analysis would also be the guideline for conceptual framework and hypotheses of this study in quantitative part. While, in quantitative analysis, the statistical both descriptive such as mean, frequency and percentage and inferential statistics such as regression analysis, correlation analysis and structural equation model (SEM) would be used to analyze.

\subsection{Contributions}

The result of the study can contribute to digital cultural and entertainment producers to design messages and contents along with deeper understand about cultural acceptance and learning about culture from foreign consumers.

\section{REFERENCES}

[1] Altheide, D. and Snow, R., 1991. Media Worlds In The Postjournalism Era. New York, N.Y.: Gruyter, Walter de, \& Co.

[2] Bury, R. and Li, J., 2013. Is it live or is it timeshifted, streamed or downloaded? Watching television in the era of multiple screens. New Media \& Society, 17(4), pp.592-610.

[3] Dwyer, T. 2019. Audiovisual translation and fandom. In L. Pérez-González (Ed.), The Routledge handbook of audiovisual translation(pp. 436-452). Routledge.

[4] Fu , F., Juntaronanont, P., Imsamran, T., \& Tian , Y. 2020. A Study on The Influence of Chinese Movies and TV series in Thailand : A Case Study of Huachiew Chalermprakiat University. Journal of Chinese Language and Culture, Huachiew Chalermprakiet University, 7(1), 213-224.

[5] Gerbner, G., Gross, L., Morgan, M., Signorielli, N., \& Shahnahan, J. (2002). Growing up with television:Cultivation process. InJ. Bryant\&D.Zillmann(Eds.),Media effects: Advances in theory and research(pp. 43-67). Mahwah, NJ: Erlbaum.

[6] Gevorgyan, G. and Manucharova, N., 2015. The effects of cultural appeal, product involvement, and ethnic identity on attitudes and recall in online advertising. Chinese Journal of Communication, 8(2), pp.196-220.

[7] Gong, Y., Ma, M., Hsiang, T. and Wang, C., 2020. Sustaining International Students' Learning of Chinese in China: Shifting Motivations among New Zealand Students during Study Abroad. Sustainability, 12(15), p.6289.

[8] Huang, Jianhua. 2015. Exploring the Reasons of Popularity of Time-Travel TV Series in Chinese University Students. Creative Education. 06, pp.1233-1236. 10.4236/ce.2015.611121.

[9] Keane, Michael. 2019. China's digital media industries and the challenge of overseas markets, Journal of Chinese Cinemas, 13:3, 244-256, DOI:10.1080/17508061.2019.1678480

[10] Li, Nai-Se. 2013. Gratification obtained from television shows on Internet TV and conventional TV. Graduate Theses and Dissertations. 13076. 
[11] Papacharissi, Zizi. 2009. "Uses and Gratifications", in An Integrated Approach to Communication Theory and Research, ed. Don Stacks and Michael Salwen (New York: Routledge), 137.

[12] Pearson, R., 2010. Fandom in the digital era. Popular Communication8(1): 84-95.

[13] Petersen, Theodore G. 2016. To binge or not to binge: A qualitative analysis of college students' binge watching habits. Florida Communication Journal 44: 77-88.

[14] Rubin, A., 1983. Television uses and gratifications: The interactions of viewing patterns and motivations. Journal of Broadcasting, 27(1), pp.37-51.

[15] Shim, A., Yecies, B., Ren, X. and Wang, D., 2020. Cultural intermediation and the basis of trust among webtoon and webnovel communities. Information, Communication \& Society, 23(6), pp.833-848.

[16] Stafford, T. F., Stafford, M .R. and Schkade L. L. 2004. "Determining Uses and Gratifications for the Internet," Decision Sciences (35:2), pp. 259-288.

[17] Steiner, E. and Xu, K., 2018. Binge-watching motivates change: Uses and gratifications of streaming video viewers challenge traditional TV research. Convergence: The International Journal of Research into New Media Technologies, 26(1), pp.82-101.

[18] Taddese, E., 2019. A Study on Students' Motivation to Learn Chinese Culture Course: The Case of 2018 Northeast Normal University International Students. Education Quarterly Reviews, 2(1).

[19] Thomas, B., 2011. 'Update Soon!' Harry Potter fanfiction and narrative as a participatory process. In: Page R and Thomas B (eds) New Narratives: Stories and Storytelling in the Digital Age. Lincoln, NE: University of Nebraska Press, pp. 205-219.

[20] Tian, X. and Adorjan, M., 2016. Fandom and coercive empowerment: the commissioned production of Chinese online literature. Media, Culture \& Society, 38(6), pp.881-900.

[21] Walton-Pattison, E., Dombrowski, S. and Presseau, J., 2016. 'Just one more episode': Frequency and theoretical correlates of television binge watching. Journal of Health Psychology, 23(1), pp.17-24.

[22] Wang, Y., 2020. Involving Cultural Sensitivity in the Design Process: A Design Toolkit for Chinese Cultural Products. International Journal of Art \& Design Education, 39(3), pp.565-584. 